AperTO - Archivio Istituzionale Open Access dell'Università di Torino

Benefit of Extended Dual Antiplatelet Therapy Duration in Acute Coronary Syndrome Patients Treated with Drug Eluting Stents for Coronary Bifurcation Lesions (from the BIFURCAT Registry)

This is a pre print version of the following article:

Original Citation:

Availability:

This version is available http://hdl.handle.net/2318/1800903

since 2023-02-10T15:31:05Z

Published version:

DOI:10.1016/j.amjcard.2021.07.005

Terms of use:

Open Access

Anyone can freely access the full text of works made available as "Open Access". Works made available under a Creative Commons license can be used according to the terms and conditions of said license. Use of all other works requires consent of the right holder (author or publisher) if not exempted from copyright protection by the applicable law. 


\section{Benefit of Extended Dual Antiplatelet Therapy Duration in Acute Coronary \\ Syndrome Patients Treated with Drug Eluting Stents for Coronary Bifurcation \\ Lesions (from the BIFURCAT Registry).}

Ovidio De Filippo*1 MD, Jeehoon Kang*2 MD, Francesco Bruno ${ }^{1} \mathrm{MD}$, Jung-Kyu $\mathrm{Han}^{2} \mathrm{MD}$, Andrea Saglietto ${ }^{1}$ MD, Han-Mo Yang ${ }^{2}$ MD, Giuseppe Patti ${ }^{3}$ MD, Kyung-Woo Park² MD, Radoslaw Parma ${ }^{4}$ MD, Hyo-Soo Kim² MD, Leonardo De Luca ${ }^{5}$ MD, Hyeon-Cheol Gwon ${ }^{6}$ MD, Mario lannaccone ${ }^{7}$ MD, Woo Jung Chun ${ }^{8}$ MD, Grzegorz Smolka ${ }^{4}$ MD, Seung-Ho Hur ${ }^{9}$ MD, Enrico Cerrato ${ }^{10}$ MD, Seung Hwan Han ${ }^{11}$ MD, Carlo di Mario ${ }^{12}$ MD, Young Bin Song ${ }^{6}$ MD, Javier Escaned ${ }^{13}$ MB, BCh, Ki Hong Choi ${ }^{6}$ MD, Gerard Helft ${ }^{14}$ MD, Joon-Hyung Doh $^{15} \mathrm{MD}$, Alessandra Truffa Giachet ${ }^{16} \mathrm{MD}$, Soon-Jun Hong ${ }^{17} \mathrm{MD}$, Saverio Muscoli ${ }^{18} \mathrm{MD}$, Chang-Wook Nam ${ }^{9}$ MD, Guglielmo Gallone ${ }^{1} \mathrm{MD}$, Davide Capodanno ${ }^{19} \mathrm{MD}$, Daniela Trabattoni ${ }^{20} \mathrm{MD}$, Yoichi Imori ${ }^{21} \mathrm{MD}$, Veronica Dusi $^{22} \mathrm{MD}$, Bernardo Cortese ${ }^{23} \mathrm{MD}$, Antonio Montefusco ${ }^{1} \mathrm{MD}$, Federico Conrotto ${ }^{1} \mathrm{MD}$, lacopo Colonnelli24, Imad Sheiban ${ }^{25}$ MD, Gaetano Maria de Ferrari ${ }^{1}$ MD, Bon-Kwon Koo ${ }^{2}$ MD**, Fabrizio D'Ascenzo ${ }^{1}$ MD, Phd**

*joint first authors; **joint last authors

\section{Affiliations:}

1) Division of Cardiology, Department of Medical Sciences, University of Turin, Torino, Italy

2) Department of Internal Medicine and Cardiovascular Center, Seoul National University Hospital, Seoul, Republic of Korea

3) Coronary Care Unit and Catheterization laboratory, A.O.U. Maggiore della Carità, Novara, Novara, Italy

4) Department of Cardiology and Structural Heart Diseases, Medical University of Silesia, Katowice, Poland.

5) Department of Cardiosciences, A.O. San Camillo-Forlanini, Roma, Italy

6) Department of Cardiology Sungkyunkwan University Samsung Medical Center Seoul Republic of Korea

7) Dipartimento di Cardiologia, Ospedale San Giovanni Bosco,Torino, Italy

8) Department of Internal Medicine, Samsung Changwon Hospital, Changwon, Republic of Korea

9) Department of Internal Medicine, Keimyung University Dongsan Medical Center, Daegu, Republic of Korea

10) Department of Cardiology, San Luigi Gonzaga Hospital, Orbassano, Turin, Italy

11) Division of Cardiology, Department of Internal Medicine, Gachon University Gil Hospital, Incheon, Republic of Korea

12) Structural Interventional Cardiology, Careggi University Hospital, Florence, Italy

13) Department of Cardiology, Hospital Clínico San Carlos IDISSC and Universidad Complutense de Madrid, Madrid, Spain.

14) Pierre and Marie Curie University, Paris, France

15) Division of Cardiology, Department of Internal Medicine, Inje University Ilsan Paik Hospital, Goyang, Republic of Korea

16) Division of Cardiology Ospedale di Asti, Asti, Italy

17) Department of Cardiology, Cardiovascular Center, Korea University Anam Hospital, Seoul, Republic of Korea

18) Department of Medicine, Università degli Studi di Roma 'Tor Vergata', Rome, Italy 
19) Division of Cardiology, Cardio-Thoracic-Vascular Department, Azienda Ospedaliero Universitaria "Policlinico-Vittorio Emanuele," Catania, Italy

20) Invasive Cardiology Unit 3, Centro Cardiologico Monzino, IRCCS, Milano, Italy

21) Department of Cardiovascular Medicine, Nippon Medical School, Tokyo, Japan

22) Department of Molecular Medicine, Section of Cardiology, University of Pavia, Pavia, Italy

23) Department of Interventional Cardiology, ASST Fatebenefratelli-Sacco, Milano, Italy

24) Department of Computer Science, University of Torino, Torino, Italy

25) Pederzoli Hospital, Peschiera del Garda, Italy

\section{Corresponding author:}

Bon-Kwon Koo,

Seoul National University Hospital, Seoul, South Korea, bkkoo@snu.ac.kr

The authors have no conflicts of interest to declare

Author's copy (preprint) of O. D. Filippo, J. Kang, F. Bruno, J. Han, A. Saglietto, H. Yang, G. Patti, K. Park, R. Parma, H. Kim, L. D. Luca, H. Gwon, M. lannaccone, W. J. Chun, G. Smolka, S. Hur, E. Cerrato, S. H. Han, C. di Mario, Y. B. Song, J. Escaned, K. H. Choi, G. Helft, J. Doh, A. T. Giachet, S. Hong, S. Muscoli, C. Nam, G. Gallone, D. Capodanno, D. Trabattoni, Y. Imori, V. Dusi, B. Cortese, A. Montefusco, F. Conrotto, I. Colonnelli, I. Sheiban, G. M. de Ferrari, B. Koo, and F. D'Ascenzo, "Benefit of extended dual antiplatelet therapy duration in acute coronary syndrome patients treated with drug eluting stents for coronary bifurcation lesions (from the BIFURCAT registry)," The american journal of cardiology, 2021.

doi:https://doi.org/10.1016/j.amjcard.2021.07.005 


\section{ABSTRACT.}

Optimal dual antiplatelet therapy (DAPT) duration for patients undergoing percutaneous coronary intervention (PCI) for coronary bifurcations is an unmet issue. The BIFURCAT registry was obtained by merging two registries on coronary bifurcations. Three groups were compared in a two-by-two fashion: short-term DAPT ( $\leq 6$ months), intermediate-term DAPT (6-12 months) and extended DAPT (>12 months). Major adverse cardiac events (MACE) (a composite of all-cause death, myocardial infarction (MI), target-lesion revascularization and stent thrombosis) were the primary endpoint. Single components of MACE were the secondary endpoints. Events were appraised according to the clinical presentation: chronic coronary syndrome (CCS) vs acute coronary syndrome (ACS). 5537 patients (3231 ACS, 2306 CCS) were included. After a median follow-up of 2.1 years (IQR 0.9-2.2), extended DAPT was associated with a lower incidence of MACE compared with intermediate-term DAPT (2.8\% vs 3.4\%, adjusted HR 0.23 [0.1-0.54], $p<0.001)$, driven by a reduction of allcause death in the ACS cohort. In the CCS cohort, an extended DAPT strategy was not associated with a reduced risk of MACE. In conclusion, among real-world patients receiving $\mathrm{PCl}$ for coronary bifurcation, an extended DAPT strategy was associated with a reduction of MACE in ACS but not in CCS patients.

Keywords: Dual antiplatelet therapy; percutaneous coronary intervention; coronary bifurcation lesions. 


\section{INTRODUCTION.}

Coronary bifurcation stenosis account for $15-20 \%$ of lesions treated with percutaneous coronary intervention $(\mathrm{PCl})^{1}$. Despite $\mathrm{PCl}$ is currently a routine practice in this setting ${ }^{2}$, it has been historically characterized by a lower procedural success rate and worse clinical outcomes as compared with stenting of noncomplex coronary lesions ${ }^{3}$. The most suitable dual antiplatelet therapy (DAPT) strategy in this context, in which suboptimal procedural results (i.e. malapposed stent struts, inadequate stent expansion, excessive metal scaffolding) are often observed, is yet to be determined. Latest years' research focused on the optimal intensity and duration of antiplatelet treatments following $\mathrm{PCl}$ with discordant findings ${ }^{4-5}$, mostly suggesting that the benefit of an extended DAPT strategy is modulated by the individual thrombotic risk and by clinical presentation. Yet, patients with high-risk anatomical features such as coronary bifurcation lesions or unprotected left main (ULM) involvement were mostly underrepresented or excluded in these trials, thus limiting the inferential aim of these findings in the context of complex coronary disease. Consequently, we explored the impact of different DAPT duration strategy in a large cohort of patients treated with $\mathrm{PCl}$ with $\mathrm{DES}$ for coronary bifurcation lesions across different clinical presentations.

\section{METHODS.}

Two large datasets (COBIS III, NCT01642992 and RAIN, NCT03544294) of patients treated with $\mathrm{PCl}$ for coronary bifurcations were merged in prespecified forms to create the BIFURCAT (comBined Insights From the Unified RAIN and COBIS bifurcAtion regisTries) registry, encompassing 5537 patients. Details about both registries are reported in the 
supplementary appendix. Patients were classified in groups based on DAPT duration after $\mathrm{PCl}$ and to evaluate prognosis from landmark time-points. We identified three groups of interest:

Short-term DAPT: patients with a DAPT duration $\leq$ six months

Intermediate-term DAPT: patients with a DAPT duration > six months and

Extended DAPT: patients with a DAPT duration > 12 months

The groups were compared in a two-by-two fashion. For each comparison only the events occurring after the shortest landmark time-point of DAPT withdrawal after $\mathrm{PCl}$ were accounted for. For instance, to compare outcomes of intermediate-term DAPT vs short-term DAPT, only events occurring after 6 months were considered. Likewise, to compare extended-term DAPT vs intermediate-term DAPT we only included events occurring after 12 months. Details about $\mathrm{PCl}$, pharmacologic therapy and data collection are reported in the supplementary appendix (see supplementary methods). Major adverse cardiac events [(MACE), defined as a composite of all-cause death, myocardial infarction (MI), target-lesion revascularization (TLR) and definite or probable stent thrombosis (ST)] were the primary endpoint. Single outcomes constituting the composite of MACE were the secondary endpoints. All clinical events were classified based on the recommendations from the Academic Research Consortium (ARC) ${ }^{6}$. Endpoints of interest were appraised according to the clinical presentation (ACS vs chronic coronary syndrome, CCS). Subgroup analyses according to the presence of disease involving distal ULM, DAPT score ${ }^{7}$ and stenting technique (provisional vs 2 stents) were also performed. Categorical variables are reported as count and percentages. Continuous variables as mean and standard deviations or interquartile range (IQR). Parametric (T-test) and non-parametric (Mann-Whitney test) tests were used to assess differences between continuous variables, while chi-square test was 
used for categorical variables. Adjustement was performed with Cox multivariate analysis and inverse probability of treatment weighting (IPTW). For Cox multivariate analysis, variables with significant differences at univariate analysis $(p<0.05)$ or clinically relevant were included in the multivariable model, along with the referral registry (COBIS vs. RAIN) and the year of enrolment (meant as before and after 2015). Adjusted survival analysis with Cox adjustment was performed for MACE. For IPTW, the following steps were performed: (a) variables with $>10 \%$ missing values were excluded from the merged study dataset; (b) multiple imputation was carried with polytomous logistic regression, logistic regression using the $\mathrm{R}$ mice package (version 3.8.0), leading to five imputed different datasets; (c) matching and weighting of the multiple imputed datasets were performed using the $R$ MatchThem package (version 0.9.3), (d) Rubin's rule was used to get pooled propensity score-adjusted hazard ratio (HR) estimates for each endpoint according to this method. A formal sample size calculation is reported in the appendix. The a priori statistical significance level was set at $\alpha=0.05$. Statistical analyses were conducted using $R$ Statistical Software version 3.6.3 (R Foundation for Statistical Computing, Vienna, Austria) and SPSS (version 24.0, SPSS Inc., Chicago, Illinois, US).

\section{RESULTS}

A total of 5537 patients were included in the final population (Figure 1): 3231 (58\%) presenting with ACS and 2306 (42\%) with CCS. The median follow-up was 2.1 years (IQR 0.9-2.2). 204 patients (3.8\%) were lost at follow up and therefore not considered for the outcome analysis. Most of the patients enrolled before 2015 were treated with extended DAPT, whereas starting from 2015 onwards the majority both in ACS and CCS subgroup received intermediate-term DAPT, (Appendix Tables 1 and 2). In the ACS cohort, 238 (7\%) patients received short-term DAPT (median length of DAPT 3 months, IQR 1-4), 1536 (48\%) intermediate-term DAPT (12 months, IQR 12-12) and 1457 (45\%) extended DAPT (24 
months, IQR 23-24). In the CCS cohort, 144 (6\%) patients received short-term DAPT (median length 1 month, IQR 1-3), 1208 (52\%), intermediate-term DAPT (12 months, IQR 12-12) and 954 (42\%) extended DAPT (24 months, IQR 23-24). Baseline clinical features are reported in Table 1. Procedural features are outlined in Supplementary Table 3. Among ACS patients, extended DAPT was associated with a lower incidence of MACE as compared with intermediate-term DAPT ( $2.8 \%$ vs. $3.4 \%$, adjusted HR $0.23,95 \% \mathrm{Cl} 0.11$ $0.54, \mathrm{p}<0.001$ and adjusted HR $0.27,95 \% \mathrm{Cl} 0.18-0.43, \mathrm{p}$ 0.04, with Cox multivariate analysis and with IPTW, respectively). No significant differences were observed in the incidence of MACE when comparing the intermediate-term DAPT group with the short-term DAPT group (5.3\% vs 8\%, HR 0.45, 95\% Cl 0.29-1.32, p 0.17 and HR $0.6795 \% \mathrm{Cl} 0.33$ 1.34, $\mathrm{p}=0.26$ after Cox multivariate adjustment and IPTW, respectively), Table 2 and Figure 2. For CCS patients, extended DAPT and intermediate DAPT regimens were not associated with a reduced risk of MACE after multivariate as well as IPTW adjustment (Table 2 and Figure 2). Among ACS patients, extended DAPT compared with intermediateterm DAPT was associated with a reduced risk of all-cause death after Cox multivariate adjustment (1.4\% vs. $1.6 \%$, HR $0.16,95 \% \mathrm{Cl} 0.04-0.9$, p 0.04) but not at IPTW analysis (HR 0.86, 95\% Cl 0.64-1.73, p 0.71), Table 2. No differences were observed between the intermediate and the short-term DAPT groups. For CCS patients, a similar adjusted risk of all-cause death was observed among the three subgroups when compared in a two-by-two fashion, Table 2. A lower unadjusted incidence of MI ( $0.6 \%$ vs $0.9 \%)$, TLR ( $0.9 \%$ vs $1.4 \%)$ and ST $(0.1 \%$ vs $0.3 \%)$ was observed among ACS patients treated with an extended DAPT strategy as compared with those treated with DAPT for 6-12 months, Table 2. However, such differences were not significant after IPTW adjustment. Among CCS patients, a lower incidence of ST was observed with longer DAPT regimens ( $0.5 \%$ vs $1.4 \%$ for intermediate DAPT vs short-DAPT and $0 \%$ vs $0.4 \%$ for extended DAPT vs intermediate DAPT), with a significant difference for patients treated for 6-12 months as compared to those on DAPT 
for $\leq 6$ months after IPTW adjustment (HR 0.14 95\%Cl 0.03-0.74, $\mathrm{p}=0.02)$, but not with Cox multivariate analysis ( $\mathrm{HR} 0.45,95 \% \mathrm{Cl} 0.04-4.34, \mathrm{p}=0.66)$. The risk of $\mathrm{MI}$ and TLR according to DAPT duration subgroups within the CCS cohort was not significantly different.

In the ACS cohort, extended DAPT reduced the risk of MACE compared with intermediateterm DAPT for all the subgroups explored (ULM vs non-ULM, stenting strategy and DAPT score $<$ or $\geq 2$ ). Intermediate-term DAPT compared to short-term DAPT reduced the risk of MACE only for patients with DAPT score $\geq 2$ (HR 0.36, 95\% Cl 0.13-0.99, p 0.04), while there were no differences in the other subgroups analyzed (Figure 3, panel A and Appendix Table 4). In the CCS cohort, no differences in MACE incidence according to DAPT duration were observed across all the explored subgroups (Figure 3, panel B and Appendix Table 4).

\section{DISCUSSION}

The main findings of this study, investigating the issue of the optimal DAPT duration in patients treated with $\mathrm{PCl}$ for coronary bifurcation according to clinical presentation can be resumed as follows: ACS patients undergoing $\mathrm{PCI}$ for coronary bifurcation lesions who received an extended (>12 months) DAPT had a lower incidence of MACE compared with those treated with an intermediate-term DAPT (6-12 months); the lower incidence of MACE in ACS patients receiving DAPT for > 12 months compared to those receiving DAPT for of 6-12 months was confirmed after multivariate and IPTW adjustment and was consistent despite the stenting technique (one vs 2 stents), the site of bifurcation (ULM vs no ULM) and the DAPT score. Furthermore, a higher incidence of MACE was observed in patients with a DAPT score $\geq 2$ and a DAPT duration $\leq 6$ months compared to those treated for 6-12 months. A similar risk of MACE was instead observed among patients admitted for CCS and treated with different DAPT regimens. Such result was confirmed among all the analyzed subgroups. 
Complex interventional scenarios intuitively represent a driver in favor of a prolonged antithrombotic treatment, although actual evidence supporting this approach is scant. The current ESC guidelines mostly rely on patients' clinical presentation (ACS vs CCS) to recommend a diversification in DAPT strategy, with a weak recommendation to consider prolonged DAPT duration in patients undergoing complex $\mathrm{PCI}$ (class of recommendation $\mathrm{llb})^{8}$. Such indication relies on a pooled analysis of six RCTs assessing the impact of DAPT duration according to $\mathrm{PCI}$ complexity (frequently but not always on the basis of a bifurcation treatment), where authors found that patients who underwent complex PCI had a two-fold increase risk of MACE (5.0\% vs. $2.5 \% ; P=0.001)$ and that long-term DAPT $(\geq 12$ months) compared with short-term (3 or 6 months) was associated with a reduction in MACE in this group as compared with the noncomplex $\mathrm{PCl}$ cohort at a median follow up of 392 days ${ }^{9}$. Of interest, despite a non-significant interaction, the benefit of prolonged DAPT among complex $\mathrm{PCl}$ groups appeared more relevant in high-risk ACS patients (HR 0.37, 95\% $\mathrm{Cl} 0.16-0.83$ ) as compared with those admitted for unstable angina ( $\mathrm{HR} 0.75,95 \% \mathrm{Cl} 0.45-1.23$ ), thus being overall consistent with our findings. In a previous analysis from the COBIS registry, Jang et $\mathrm{al}^{10}$ found that a prolonged DAPT (>12 months) was associated with a reduction in $\mathrm{MI}$ and all-cause death as compared to DAPT $<12$ months. However, in contrast with such work, we found the admission diagnosis to modulate this benefit with only ACS patients taking advantage from a long-term antithrombotic treatment. Both patient- (clinical presentation and extent of $\mathrm{CAD}$ ) and procedural-related ( $\mathrm{PCl}$ complexity) features may influence the future thrombotic risk and therefore the overall clinical benefit of an extended DAPT regimen. The extended cohort considered in the BIFURCAT registry as compared with the solely COBIS population is characterized by a larger use of very-thin strut-stents (as per RAIN registry inclusion criteria) ${ }^{11}$. This difference may have translated in the selection of a cohort in whom patients-related factors (rather than stent- and lesion-related 
features) had a dominant role in driving the benefit of a prolonged DAPT regimen, thus probably accounting for the different findings according to the clinical admission setting. In accordance with such hypothesis, we found a significant reduction of MACE in ACS patients treated with extended DAPT regardless of the stenting technique (one vs 2 stent) used. RCTs in the modern DES era showed that short-term DAPT should be considered as the safest strategy, being consistently associated with a significant reduction in bleeding events without increase in ischemic events, both in the ACS setting and in unselected cohorts ${ }^{12-14}$. Of note, none of these trials was specifically designed to determine the optimal DAPT duration in complex anatomical settings and patients with coronary bifurcations were therefore underrepresented $(20 \%$ and $15 \%$ in HOST-REDUCE-ACS and TICO trial, respectively). Moreover, in a post-hoc analysis of the TWILIGHT Trial, among 2342 patients undergoing complex PCl who completed three months of DAPT, the continuation of ticagrelor monotherapy was associated with a lower incidence of bleeding events without increasing the risk of ischemic events as compared to continuing DAPT ${ }^{15}$. However, such analysis was not adequately powered for ischemic endpoints and differently from the BIFURCAT population patients with STEMI were not included as per study protocol inclusion criteria. In our ACS cohort, the reduction of all-cause mortality may suggest that in peculiar settings like coronary bifurcation disease, the benefits from reducing ischemic events may offset the potential increase in bleeding risk with prolonged DAPT. Such hypothesis should be further confirmed in future studies and should be interpreted with caution in the absence of data about bleeding events.

Our results should be interpreted in the context of some limitations. First, this study has an observational design. The choice of different DAPT strategies was not based on randomization. Despite IPTW adjustment, a potential bias coming from unmeasured variables that would be adequately prevented only through a randomized design cannot be excluded. However, to our knowledge no RCT is currently ongoing to address the issue of 
optimal DAPT duration in the specific setting of coronary bifurcations. Second, data on bleeding events were not available. We inferred the net clinical benefit of a prolonged DAPT strategy by performing a subgroup analysis according to DAPT score. Despite our findings were consistent with the main analysis, the potential harm coming from such strategy could not be directly assessed. Due to the observational nature of the study, the groups analyzed were not balanced in their size, especially regarding the short-term DAPT group. However, this may reflect the contemporary practice and the physicians' preference for a long-term DAPT in this setting. In conclusion, in this large real-world cohort of patients treated with $\mathrm{PCl}$ on bifurcation coronary lesions we found that an extended DAPT strategy (>12 months) compared with a short- and intermediate-term DAPT ( $<6$ months and 6-12 months, respectively) was associated with a reduction of MACE in patients admitted with ACS, regardless of DAPT score, distal ULM involvement and stenting technique (provisional vs two stents). In patients admitted for CCS, the risk of MACE was not affected by DAPT duration, but the risk of all-cause death was significantly lower in the extend-term DAPT group compared to the short-term DAPT group. These results suggest that a prolonged DAPT strategy may improve long-term clinical outcomes in patients treated with $\mathrm{PCl}$ for bifurcation coronary lesions, particularly in the setting of ACS.

\section{Acknowledgments}

None

\section{Supplementary material}

Supplementary material associated with this article can be found in the online version at https://doi.org/10.1016/i.amjcard.2021.07.005.

\section{Sources of funding}

COBIS III registry was founded by the Korean Society of Interventional Cardiology, Seoul, Republic of Korea, The Korea Health Technology R\&D Project through the Korea Health 
Industry Development Institute, and the Ministry of Health \& Welfare, Republic of Korea (grant number: HI10C2020).

\section{REFERENCES:}

1. Latib, A. \& Colombo, A. Bifurcation Disease. What Do We Know, What Should We Do? JACC Cardiovasc Interv 2008; 1, 218-226.

2. Gaido L, D'Ascenzo F, Imori Y, Wojakowski W, Saglietto A, Figini F, Mattesini A, Trabattoni D, Rognoni A, Tomassini F, Bernardi A, Ryan N, Muscoli S, Helft G, De Filippo O, Parma R, De Luca L, Ugo F, Cerrato E, Montefusco A, Pennacchi M, Wańha W, Smolka G, de Lio G, Bruno F, Huczek Z, Boccuzzi G, Cortese B, Capodanno D, Omedè P, Mancone M, Nuñez-Gil I, Romeo F, Varbella F, Rinaldi M, Escaned J, Conrotto F, Burzotta F, Chieffo A, Perl L, D'Amico M, di Mario C, Sheiban I, Gagnor A, Giammaria M, De Ferrari GM. Impact of Kissing Balloon in Patients Treated With Ultrathin Stents for Left Main Lesions and Bifurcations: An Analysis From the RAIN-CARDIOGROUP VII Study. Circ Cardiovasc Interv 2020;13(3):e008325.

3. Nakazawa G, Yazdani SK, Finn AV, Vorpahl M, Kolodgie FD, Virmani R. Pathological Findings at Bifurcation Lesions. The Impact of Flow Distribution on Atherosclerosis and Arterial Healing After Stent Implantation. J Am Coll Cardiol 2010; 55, 1679-1687.

4. Palmerini T, Della Riva D, Benedetto U, Bacchi Reggiani L, Feres F, Abizaid A, Gilard 
M, Morice MC, Valgimigli M, Hong MK, Kim BK, Jang Y, Kim HS, Park KW, Colombo A, Chieffo A, Sangiorgi D, Biondi-Zoccai G, Généreux P, Angelini GD, Pufulete M, White J, Bhatt DL, Stone GW. Three, six, or twelve months of dual antiplatelet therapy after DES implantation in patients with or without acute coronary syndromes: an individual patient data pairwise and network meta-analysis of six randomized trials and 11473 patients. Eur Heart J 2017;38(14):1034-1043.

5. Khan SU, Singh M, Valavoor S, Khan MU, Lone AN, Khan MZ, Khan MS, Mani P, Kapadia SR, Michos ED, Stone GW, Kalra A, Bhatt DL. Dual Antiplatelet Therapy After Percutaneous Coronary Intervention and Drug-Eluting Stents: A Systematic Review and Network Meta-Analysis. Circulation 2020;142(15):1425-1436.

6. Cutlip DE, Windecker S, Mehran R, Boam A, Cohen DJ, van Es GA, Steg PG, Morel MA, Mauri L, Vranckx P, McFadden E, Lansky A, Hamon M, Krucoff MW, Serruys PW; Academic Research Consortium. Clinical end points in coronary stent trials: a case for standardized definitions. Circulation 2007; 115(17):2344-2351.

7. Yeh RW, Secemsky EA, Kereiakes DJ, Normand SL, Gershlick AH, Cohen DJ, Spertus JA, Steg PG, Cutlip DE, Rinaldi MJ, Camenzind E, Wijns W, Apruzzese PK, Song Y, Massaro JM, Mauri L; DAPT Study Investigators. Development and Validation of a Prediction Rule for Benefit and Harm of Dual Antiplatelet Therapy Beyond 1 Year After Percutaneous Coronary Intervention. JAMA 2016;315(16):1735-1749.

8. Valgimigli M, Bueno H, Byrne RA, Collet JP, Costa F, Jeppsson A, Jüni P, Kastrati A, Kolh P, Mauri L, Montalescot G, Neumann FJ, Petricevic M, Roffi M, Steg PG, Windecker S, Zamorano JL, Levine GN; ESC Scientific Document Group; ESC Committee for Practice Guidelines (CPG); ESC National Cardiac Societies. 2017 ESC focused update on dual antiplatelet therapy in coronary artery disease developed in 
collaboration with EACTS: The Task Force for dual antiplatelet therapy in coronary artery disease of the European Society of Cardiology (ESC) and of the European Association for Cardio-Thoracic Surgery (EACTS). Eur Heart J 2018;39(3):213-260

9. Giustino G, Chieffo A, Palmerini T, Valgimigli M, Feres F, Abizaid A, Costa RA, Hong MK, Kim BK, Jang Y, Kim HS, Park KW, Gilard M, Morice MC, Sawaya F, Sardella G, Genereux P, Redfors B, Leon MB, Bhatt DL, Stone GW, Colombo A. Efficacy and Safety of Dual Antiplatelet Therapy After Complex PCI. J Am Coll Cardiol 2016;68(17):1851-1864

10. Jang WJ, Ahn SG, Song YB, Choi SH, Chun WJ, Oh JH, Cho SW, Kim BS, Yoon JH, Koo BK, Yu CW, Jang YS, Tahk SJ, Kim HS, Gwon HC, Lee SY, Hahn JY. Benefit of Prolonged Dual Antiplatelet Therapy After Implantation of Drug-Eluting Stent for Coronary Bifurcation Lesions: Results From the Coronary Bifurcation Stenting Registry II. Circ Cardiovasc Interv 2018;11(7):e005849.

11. D'Ascenzo F, Omedè P, De Filippo O, Cerrato E, Autelli M, Trabattoni D, Ryan N, Venuti G, Muscoli S, Montabone A, Wojakowski W, Rognoni A, Helft G, Gallo D, Parma R, De Luca L, Figini F, Mitomo S, Boccuzzi G, Mattesini A, Wańha W, Smolka G, Huczek Z, Cortese B, Sheiban I, Escaned J, Biolè C, Conrotto F, Templin C, Quadri G, Rolfo C, Capodanno D, Chieffo A, Nuñez-Gil I, Morbiducci U, lannaccone M, Gili S, Mario CD, Moretti C, D'Amico M, Varbella F, Romeo F, Lüscher TF. Impact of Final Kissing Balloon and of Imaging on Patients Treated on Unprotected Left Main Coronary Artery With Thin-Strut Stents (From the RAIN-CARDIOGROUP VII Study). Am J Cardiol 2019;123(10):1610-1619.

12. Kim BK, Hong SJ, Cho YH, Yun KH, Kim YH, Suh Y, Cho JY, Her AY, Cho S, Jeon DW, Yoo SY, Cho DK, Hong BK, Kwon H, Ahn CM, Shin DH, Nam CM, Kim JS, Ko 
YG, Choi D, Hong MK, Jang Y; TICO Investigators. Effect of Ticagrelor Monotherapy vs Ticagrelor With Aspirin on Major Bleeding and Cardiovascular Events in Patients With Acute Coronary Syndrome: The TICO Randomized Clinical Trial. JAMA 2020;323(23):2407-2416

13. Kim HS, Kang J, Hwang D, Han JK, Yang HM, Kang HJ, Koo BK, Rhew JY, Chun KJ, Lim YH, Bong JM, Bae JW, Lee BK, Park KW; HOST-REDUCE-POLYTECH-ACS investigators. Prasugrel-based de-escalation of dual antiplatelet therapy after percutaneous coronary intervention in patients with acute coronary syndrome (HOSTREDUCE-POLYTECH-ACS): an open-label, multicentre, non-inferiority randomised trial. Lancet 2020;396(10257):1079-1089.

14. Mauri L, Kereiakes DJ, Yeh RW, Driscoll-Shempp P, Cutlip DE, Steg PG, Normand SL, Braunwald E, Wiviott SD, Cohen DJ, Holmes DR Jr, Krucoff MW, Hermiller J, Dauerman HL, Simon DI, Kandzari DE, Garratt KN, Lee DP, Pow TK, Ver Lee P, Rinaldi MJ, Massaro JM; DAPT Study Investigators. Twelve or 30 months of dual antiplatelet therapy after drug-eluting stents. N Engl J Med 2014;371(23):2155-2166.

15. Dangas G, Baber U, Sharma S, Giustino G, Mehta S, Cohen DJ, Angiolillo DJ, Sartori S, Chandiramani R, Briguori C, Dudek D, Escaned J, Huber K, Collier T, Kornowski R, Kunadian V, Kaul U, Oldroyd K, Sardella G, Shlofmitz R, Witzenbichler B, Ya-Ling H, Pocock S, Gibson CM, Mehran R. Ticagrelor With or Without Aspirin After Complex PCl. J Am Coll Cardiol 2020;75(19):2414-2424 


\section{TABLES:}

Table 1: Baseline features of the population.

\begin{tabular}{|c|c|c|c|c|c|c|c|c|c|}
\hline \multirow[t]{3}{*}{ VARIABLE } & \multicolumn{4}{|c|}{ ACS cohort } & \multicolumn{4}{|c|}{ CCS cohort } & \\
\hline & \multicolumn{4}{|c|}{ Months of dual antiplatelet therapy } & \multicolumn{4}{|c|}{ Months of dual antiplatelet therapy } & \\
\hline & $\begin{array}{l}\leq 6 \text { months } \\
(238,7 \%)\end{array}$ & $\begin{array}{l}6-12 \text { months } \\
(1536,48 \%)\end{array}$ & $\begin{array}{l}>12 \text { months } \\
(1457,45 \%) \\
\end{array}$ & p-value & $\begin{array}{l}<6 \text { months } \\
(144,6 \%)\end{array}$ & $\begin{array}{l}6-12 \text { months } \\
(1208,52 \%)\end{array}$ & $\begin{array}{l}>12 \text { months } \\
(954,42 \%)\end{array}$ & p-value & \\
\hline Age (years) & $69 \pm 13$ & $68 \pm 13$ & $63 \pm 11$ & $<0.001$ & $64 \pm 11$ & $66 \pm 10$ & $67 \pm 106$ & 0.56 & \\
\hline Male gender & $179(75.5 \%)$ & $1151(74.9 \%)$ & $1098(75.4 \%)$ & 0.947 & $113(79.0 \%)$ & $945(78.2 \%)$ & $742(77.8 \%)$ & 0.938 & \\
\hline Hypertension & $157(66.2 \%)$ & $1129(73.5 \%)$ & $795(54.6 \%)$ & $<0.001$ & $102(71.3 \%)$ & $902(74.6 \%)$ & $572(60.0 \%)$ & $<0.001$ & \\
\hline Hyperlipidemia & $93(39.2 \%)$ & $866(56.3 \%)$ & $550(37.7 \%)$ & $<0.001$ & $81(56.6 \%)$ & $744(61.5 \%)$ & $402(42.1 \%)$ & $<0.001$ & \\
\hline Diabetes mellitus & $93(39.2 \%)$ & $506(32.9 \%)$ & $470(32.3 \%)$ & 0.104 & $48(33.6 \%)$ & $382(31.6 \%)$ & $335(35.1 \%)$ & 0.224 & \\
\hline Current smoker & $81(34.2 \%)$ & $404(26.3 \%)$ & $486(33.4 \%)$ & $<0.001$ & $22(15.4 \%)$ & $182(15.1 \%)$ & $233(24.4 \%)$ & $<0.001$ & \\
\hline $\begin{array}{l}\text { Renal disease [eGFR } \\
<60 \mathrm{ml} / \mathrm{min} \text { ] at presentation }\end{array}$ & $53(23.2 \%)$ & $330(21.5 \%)$ & $49(3.5 \%)$ & $<0.001$ & $20(14.9 \%)$ & $234(19.4 \%)$ & $32(3.5 \%)$ & $<0.001$ & \\
\hline Previous PCI & $45(19.0 \%)$ & $370(24.1 \%)$ & $173(11.9 \%)$ & $<0.001$ & $37(25.9 \%)$ & $490(40.5 \%)$ & $129(13.5 \%)$ & $<0.001$ & \\
\hline Previous CABG & $5(2.1 \%)$ & $71(4.6 \%)$ & $5(0.3 \%)$ & $<0.001$ & $10(7.0 \%)$ & $60(5.0 \%)$ & $6(0.6 \%)$ & $<0.001$ & \\
\hline Previous MI & $46(19.4 \%)$ & $480(31.2 \%)$ & $68(4.7 \%)$ & $<0.001$ & $23(16.1 \%)$ & $291(24.1 \%)$ & $36(3.8 \%)$ & $<0.001$ & \\
\hline \multirow[t]{5}{*}{ Indication to PCI } & STEMI & $58(24.5 \%)$ & $474(30.8 \%)$ & $271(18.6 \%)$ & $<0.001$ & - & - & - & \\
\hline & NSTEMI & $96(40.5 \%)$ & $662(43.1 \%)$ & $405(27.8 \%)$ & 0.03 & - & - & - & \\
\hline & UA & $83(35.0 \%)$ & $401(26.1 \%)$ & $781(53.6 \%)$ & 0.01 & - & - & - & \\
\hline & Stable angina & - & - & - & & $91(63.6 \%)$ & $714(59.1 \%)$ & $953(99.9 \%)$ & $<0.001$ \\
\hline & Other & - & - & - & & $52(36.4 \%)$ & $495(40.9 \%)$ & $1(0.1 \%)$ & $<0.001$ \\
\hline
\end{tabular}

Legend: ACS: acute coronary syndrome; CCS: Chronic Coronary Syndrome; eGFR: estimated glomerular filtration rate; PCI: percutaneous coronary intervention; CABG: coronary artery bypass graft; MI: myocardial infarction; STEMI: ST-segment elevation myocardial; NSTEMI: non ST-segment elevation myocardial infarction; UA: unstable angina. p-value for unadjusted between-group comparisons. 
Table 2: Long term outcomes.

\begin{tabular}{|c|c|c|c|c|c|c|}
\hline & \multicolumn{3}{|c|}{ ACS cohort } & \multicolumn{3}{|c|}{ CCS cohort } \\
\hline & \multicolumn{3}{|c|}{ DAPT 6-12 months versus DAPT $\leq 6$ months } & \multicolumn{3}{|c|}{ DAPT 6-12 months versus DAPT $\leq 6$ months } \\
\hline & Univariate analysis** & $\begin{array}{c}\text { Cox multivariate analysis } \\
\text { (HR, CI 95\%)* }\end{array}$ & IPTW (HR; CI 95\%) & Univariate analysis** & $\begin{array}{c}\text { Cox multivariate } \\
\text { analysis (HR, CI 95\%)* }\end{array}$ & IPTW (HR; CI 95\%) \\
\hline MACE & $5.3 \%$ versus $8.0 \%, \mathrm{p} 0.101$ & $0.45(0.29-1.32), \mathrm{p} 0.17$ & $0.67(0.33-1.34), \mathrm{p} 0.26$ & $3.6 \%$ versus $6.9 \%$ p 0.05 & $0.44(0.21-1.02)$ p 0.03 & $0.81(0.41-4.12)$ p 0.67 \\
\hline Death & $18.5 \%$ versus $5.5 \% \mathrm{p}<0.001$ & $0.48(0.21-1.3), \mathrm{p} 0.07$ & $0.47(0.10-1.15)$, p 0.09 & $3.3 \%$ versus $6.9 \%$ p 0.03 & $0.67(0.12-5.91)$ p 0.63 & $0.35(0.16-1.6)$ p 0.16 \\
\hline MI & $2.2 \%$ versus $1.3 \%, \mathrm{p} 0.34$ & $1.66(0.44-5.52), \mathrm{p} 0.56$ & $2.12(0.67-2.78), \mathrm{p} 0.07$ & $0.8 \%$ versus $0.2 \%$ p 0.27 & 0.78 (0.34-5.67.) p 0.57 & $0.89(0.71-1.67)$ р 0.31 \\
\hline TLR & $0.8 \%$ versus $1.7 \%, \mathrm{p} 0.17$ & $0.23(0.04-1.8), \mathrm{p} 0.68$ & $0.32(0.09-1.12), \mathrm{p} 0.06$ & $1.6 \%$ versus $2.1 \% \mathrm{p} 0.65$ & $0.45(0.12-4.56)$ p 0.51 & $0.44(0.11-1.82)$ p 0.99 \\
\hline ST & $0.3 \%$ versus $0.2 \% \mathrm{p} 0.56$ & $0.41(0.23-9.1), \mathrm{p} 0.45$ & $0.46(0.35-4.7), \mathrm{p} 0.89$ & $0.5 \%$ versus $1.4 \% \mathrm{p} 0.18$ & $0.45(0.04-4.34) \mathrm{p} 0.66$ & $0.14(0.03-0.74) \mathrm{p} 0.02$ \\
\hline $\begin{array}{l}\text { DAPT }>12 \text { months versus } \\
\text { DAPT } 6-12 \text { months }\end{array}$ & $\begin{array}{l}\text { DAPT }>12 \text { months versus } \\
\text { DAPT 6-12 months }\end{array}$ & & & & & \\
\hline MACE & $2.8 \%$ versus $3.4 \% \mathrm{p} 0.56$ & $0.23(0.11-0.54), \mathrm{p}<0.001$ & 0.27 (0.18-0.43), p0.04 & $3.6 \%$ versus $3.2 \%, \mathrm{p} 0.67$ & $0.51(0.31-1.45)$ p 0.78 & $1.12(0.64-1.73) \mathrm{p} 0.85$ \\
\hline Death & $1.4 \%$ versus $1.6 \% \mathrm{p} 0.81$ & $0.16(0.04-0.9), \mathrm{p} 0.04$ & $0.86(0.64-1.73), \mathrm{p} 0.71$ & $1.3 \%$ versus $1.3 \%, \mathrm{p} 0.89$ & $0.45(0.23-4.51) \mathrm{p} 0.43$ & $1.27(0.50-3.21)$ p 0.62 \\
\hline MI & $0.6 \%$ versus $0.9 \%$ p 0.08 & $0.25(0.18-0.88), \mathrm{p} 0.03$ & $1.11(0.88-3.56), \mathrm{p} 0.65$ & $0.3 \%$ versus $0.7 \%, \mathrm{p} 0.67$ & $0.31(0.03-3.41) \mathrm{p} 0-18$ & $0.33(0.21-4.12) \mathrm{p} 0.55$ \\
\hline TLR & $0.9 \%$ versus $1.4 \%$, p 0.17 & $0.45(0.21-1.7), \mathrm{p} 0.89$ & $0.79(0.36-1.81)$, p 0.55 & $1.7 \%$ versus $1.6 \&$, p 0.89 & $0.51(0.14-1.41)$ p 0.36 & $0.90(0.44-1.85)$ p 0.78 \\
\hline ST & $0.1 \%$ versus $0.3 \%, \mathrm{p} 0.28$ & $2.1(0.2-4.9), \mathrm{p} 0.67$ & $0.49(0.21-4.51), \mathrm{p} 0.66$ & $0.0 \%$ versus $0.4 \%$ p 0.04 & - & - \\
\hline
\end{tabular}

Legend:DAPT: dual antiplatelet therapy; ACS: acute coronary syndrome; CCS: Chronic Coronary Syndrome; MACE: major adverse cardiovascular events; MI: myocardial infarction; TLR: target lesion revascularization; ST: stent thrombosis. HR: hazard ratio; CI:

confidence interval; IPTW: Inverse probability of treatment weighting.

* adjusted for age, gender, hyperlipidemia, diabetes mellitus, renal disease, distal ULM, provisional versus 2 stents strategy, use of

imaging, registry (COBIS versus RAIN) kind of DAPT and 2010-2014 versus 2015-2017

** the percentages are reported as number of events/number of patients at the follow up achieved by each patient 


\section{FIGURES:}

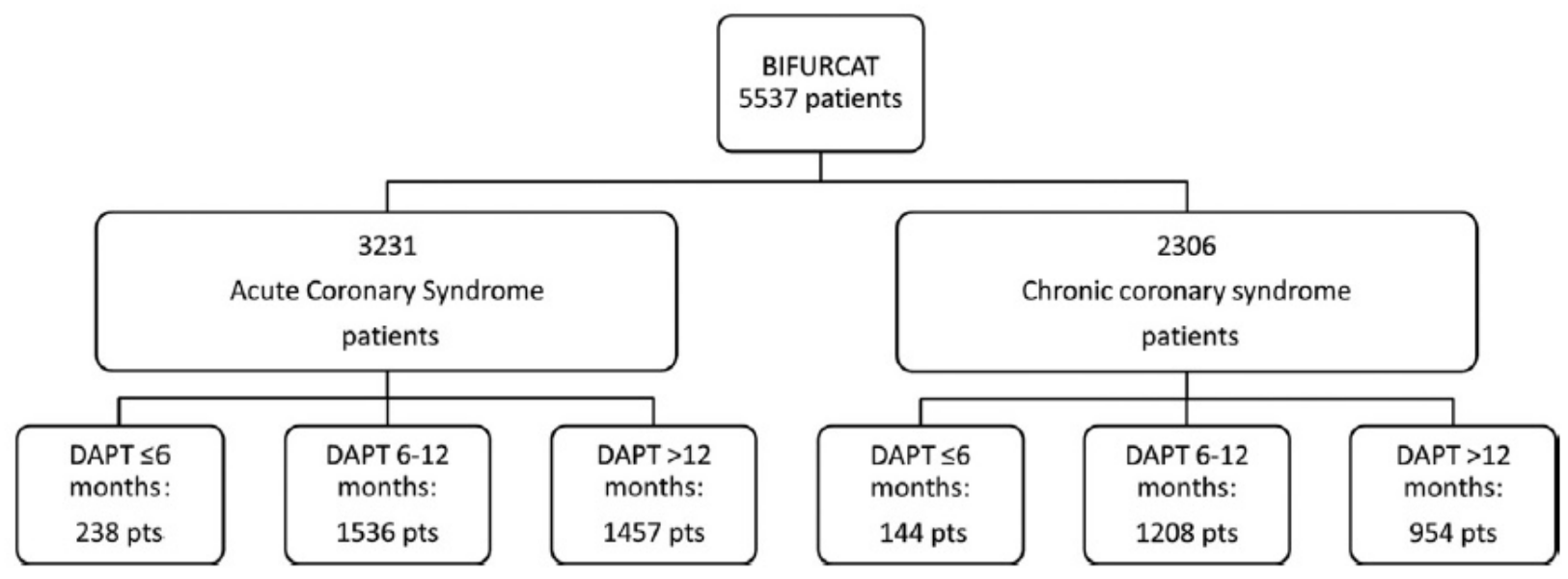

Figure 1: Study Design. DAPT: dual antiplatelet therapy.

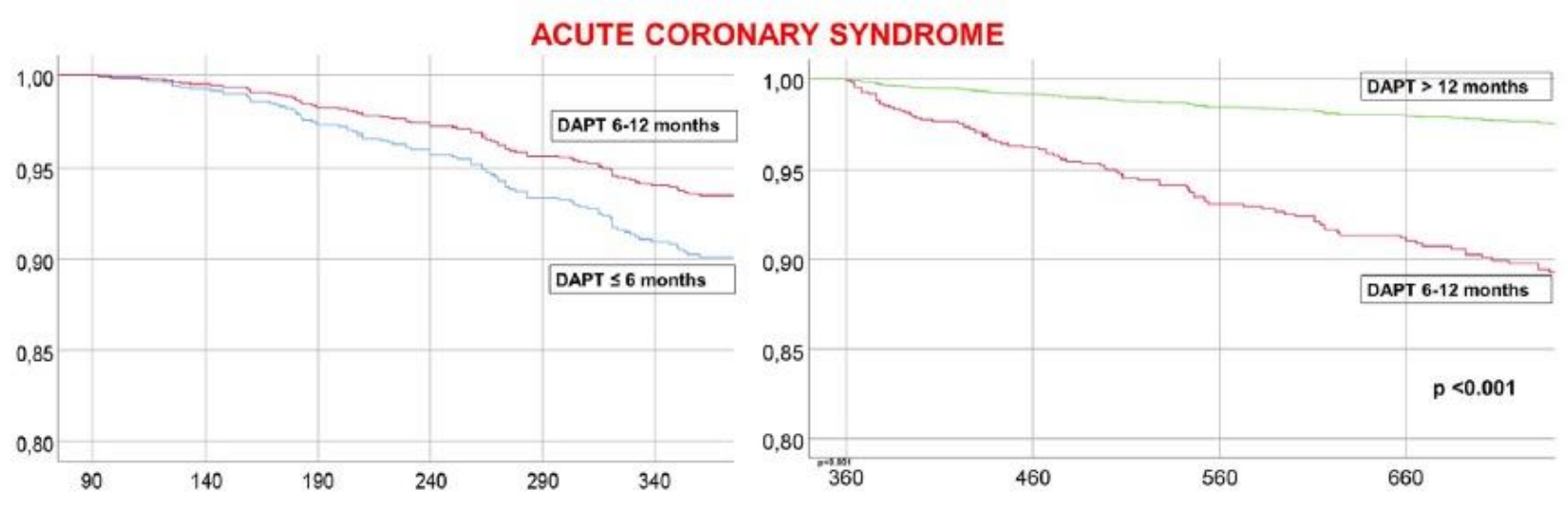

CHRONIC CORONARY SYNDROME

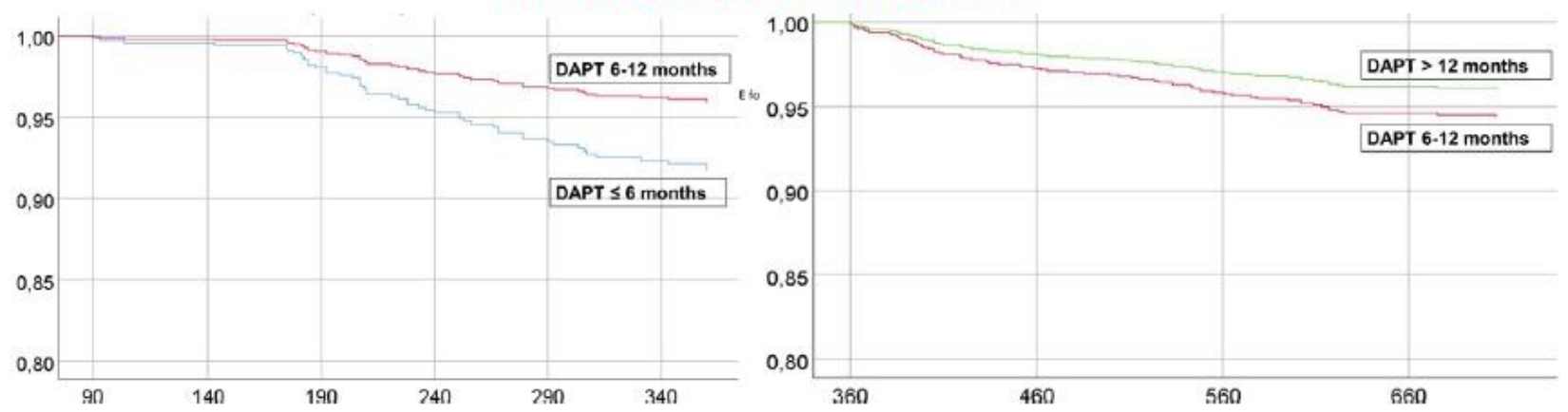

Figure 2: Adjusted survival from MACE for DAPT $\leq 6$ months, DAPT $6-12$ months and DAPT $>12$ months (above: acute coronary syndrome; below: chronic coronary syndrome cohort). Only significant $p$ values $(<0.05)$ are reported. For the comparison between DAPT $\leq 6$ months and 6-12 months, time on the $\mathrm{x}$ axis starts from 6 months after the index $\mathrm{PCl}$. For the comparison between DAPT 6-12 months and DAPT > 12 months, $x$ axis starts from 12 months after the index $\mathrm{PCl}$ procedure. 

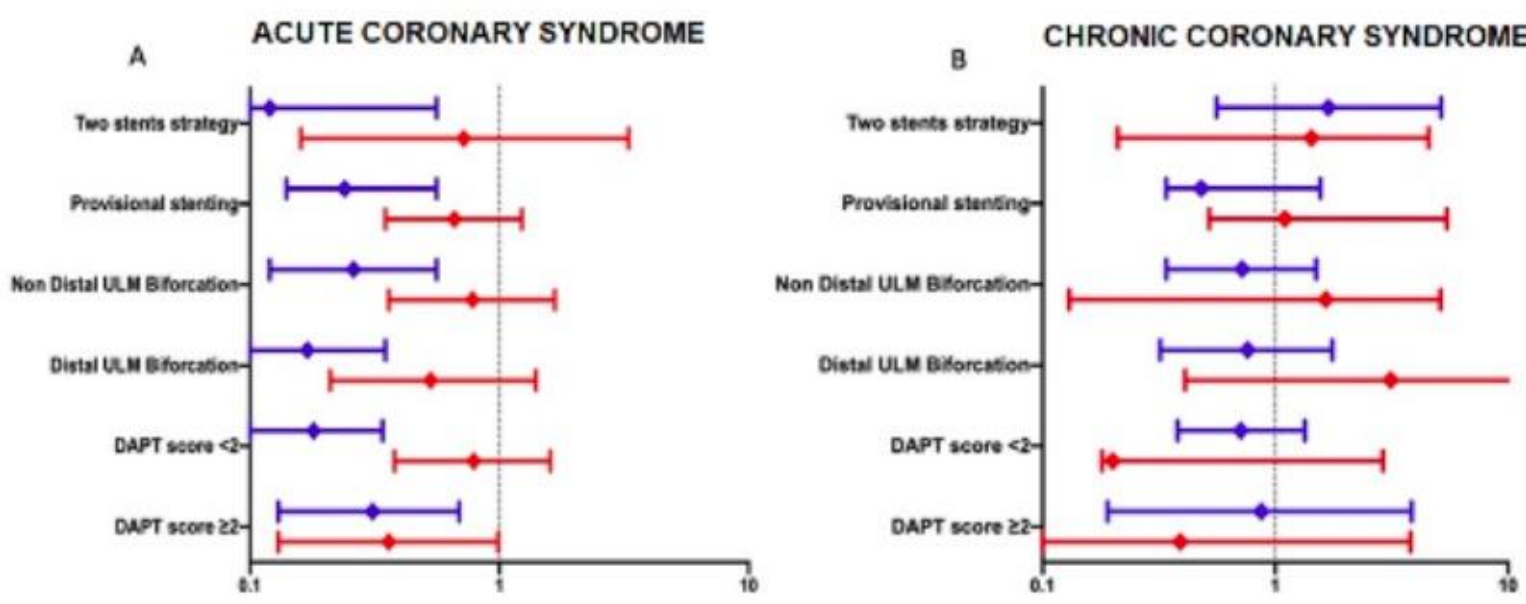

- DAPT 6-12 morths v8 <-s months

- DAPT >12 mortrs vs e-12 montis

Figure 3: Subgroup analysis for MACE. ULM: unprotected left main. DAPT: dual antiplatelet therapy 